\title{
EL TROFEO LARMA: UNA OBRA INÉDITA DEL ESCULTOR JUAN DE ÁVALOS EN UNA COLECCIÓN SEVILLANA
}

\author{
THE LARMA TROPHY: AN UNKNOWN ARTWORK BY \\ SCULPTOR JUAN DE ÁVALOS IN A SEVILLIAN COLLECTION
}

\author{
IVÁN DE LA TORRE AMERIGHI \\ Universidad de Málaga. España \\ ita@uma.es
}

\begin{abstract}
La obra inédita que damos a conocer contribuirá al mejor conocimiento de la vasta, reconocible y poco estudiada producción artística del escultor Juan de Ávalos y García-Taborda, presentando la singularidad de tratarse de una pieza de encargo empresarial, lo que condicionaría aspectos formales, iconográficos y simbólicos, para un proyecto de galardón que nunca llegó a materializarse.

Palabras clave: Juan de Ávalos; arte contemporáneo; escultura; mitología; Higea.
\end{abstract}

The unpublished artwork that we present will contribute to a better understanding of the vast, recognizable and poorly studied artistic production of the sculptor Juan de Ávalos y García-Taborda. The work, that was never materialized, presents the uniqueness of being a piece of business commission, which conditioned formal, iconographic and symbolic aspects.

Keywords: Juan de Ávalos; contemporary art; sculpture; mythology; Hygeia.

Juan de Ávalos García-Taborda (Mérida, 1911-Madrid, 2006) puede que sea uno de los artistas plásticos españoles de más dilatada, profusa y reconocible producción artística, al tiempo que el menos estudiado y más profundamente desconocido, tal vez por llevar el estigma de haber sido identificado por una única y colosal obra -los trabajos vinculados al Valle de los Caídos-como artista oficial del franquismo ${ }^{1}$, aunque asumiese numerosos proyectos de escultura monumental pública en España y América; quizá por mostrar a lo largo de toda su vida una

${ }^{1}$ DE MATEO AVILÉS, Elías: La incomprendida soledad del escultor Juan de Ávalos. Málaga, 2001, p. 11. 
fidelidad inquebrantable a unos presupuestos estéticos y a unos cánones estilísticos en unos tiempos que no le correspondían y de los que no dan cuenta las historias oficiales de la modernidad. En cierta medida, la falta de una historiografía estructurada y suficiente en torno al clasicismo escultórico, académico o no, desarrollado en España durante la segunda mitad del siglo XX, bien podría deberse a dos causas delimitadas: al compromiso de la crítica teórica de la contemporaneidad con la investigación y formulación del estilo del presente, en el entendimiento de "arte de actualidad" como aquel que, en exclusiva, atiende a pautas estéticas definidas y excluyentes marcadas por los sistemas mercantiles, y a "la coincidencia de que la promoción de la cultura pseudoimperial del franquismo"2 adoptara como recurso unos rasgos estilísticos que estereotipaban los cánones clasicistas en la búsqueda de una estética que soslayara parámetros de vanguardia.

La obra de Ávalos nunca tuvo, ni siquiera cuando fue objeto de los más altos encargos institucionales, una aceptación integral, lastrada por el elogio hueco y ampuloso de la política cultural del Régimen, siendo celosamente cuestionada por las academias cuando se encontraba en el cénit de su fama, alguno de cuyos miembros - primeras medallas- habían impulsado denuncias por desafección durante la posguerra ${ }^{3}$, llegando a ser soslayada con la llegada de la democracia por continuar haciendo pervivir, en apariencia, los ecos de un pasado que se pretendía dejar atrás. Un suspicaz revisionismo artístico-historiográfico no ha sido amable con su obra ni con sus posicionamientos formales y estéticos, ni ha atendido a mensurar contextos y entornos sociales y culturales en los cuales su producción se desenvolvió, tildando su escultura de narrativa y literaria, cuando no definiendo su quehacer "tan fácil y espectacular como pobre, con voluntad de agradar al público, sin intentos rigurosos de análisis formal..."4, asignándolo a un "miguelanguelismo desmedido y plenamente tradicional, cuando no estrictamente académico" 0 , simplemente, poniendo en cuestión sus pretendidos valores de expresión espiritual ${ }^{6}$.

En las últimas décadas, sobre todo a partir de la muerte del artista, es posible encontrar algún estudio integral ${ }^{7}$, y variadas reivindicaciones parciales, que han identificado la labor de Ávalos con posicionamientos firmes que defendían una

${ }^{2}$ MARÍN-MEDINA, José: La escultura española contemporánea (1800-1878). Historia y evaluación crítica. Madrid, 1978, pp. 193-194.

3 MORALES VALLEJO, Javier: "Juan de Ávalos. Entre la realidad y el mito", en Juan de Ávalos. Su verdad creativa. Badajoz, 1996.

${ }^{4}$ MARÍN-MEDINA, J.: La escultura española..., op. cit., p. 198.

5 BOZAL, Valeriano: Arte del siglo XX en España. T. II. Madrid, 1995, p. 65.

6 CANO DE LA IGLESIA, Jesús: "Cincuenta años de arte en Extremadura", Alcántara: revista del Seminario de Estudios Cacereños, 39, 1996, p. 63.

7 Ver BAZÁN DE HUERTA, Moisés: Juan de Ávalos: su verdad creativa. Badajoz, 1996. 
figuración idealizada, el valor y solidez del oficio tradicional, y unas virtudes de atemporalidad y trascendencia cimentadas sobre una construcción formal armónica, un canon verista y la contención emocional. Estas actitudes, que constituyeron de facto un rechazo hacia el arte deshumanizado, abstracto, conceptual o descuidado técnicamente, no implicaban, sin embargo y como el artista emeritense reconoció en primera persona, desconocimiento o desprecio hacia éstos u otros cauces expresivos plenamente contemporáneos ${ }^{8}$. De tal modo, su lenguaje ha sido reubicado y evaluado "en la línea de un realismo idealizado, que hunde sus raíces en el clasicismo y se expresa con un lenguaje sereno, claro y accesible, buscando una fácil comunicación con el público"".

La obra autógrafa que damos a conocer (Figura 1), perteneciente a la sevillana colección Marroco, y de la que no ha sido posible encontrar documentación que datase su adquisición o entrada en la misma, es una escultura modelada, realizada en barro cocido, de 40 centímetros de altura, que representa a un estilizado personaje masculino desnudo cuyo único vestido es un manto o toga que se enrosca en el antebrazo derecho y que cae por la parte delantera y trasera, bajo la cintura, cubriendo los genitales. El personaje muestra una anatomía fuerte, bien desarrollada, robusta, y una cabeza en ligero giro con respecto al torso, revelando una edad de plena madurez y unos rasgos clásicos, la nariz recta y el cabello corto y peinado hacia delante. Un árbol fuera de escala que actúa, bien como elemento sustentante, bien como fundamento simbólico, bien como recurso de decoro, cubre los glúteos del joven. Sobre la superficie de la base circular de la escultura se incluye la firma del artista -"Avalos"-, mientras en el canto de la misma resalta la inscripción "TROFEO LARMA” (Figuras 2 y 3 ).

En la mano derecha porta la figura un escudo emblema en forma de octógono irregular que muestra en relieve la copa de Higea, cáliz sobre el que se enrosca una serpiente. Higea (Hygeía), hija de Asclepio, fue una divinidad asociada con la curación, la higiene y la sanidad ${ }^{10}$. Más allá de su multivocidad y de la asociación a rasgos formales o biológicos particulares, la serpiente simboliza, por antonomasia, "la energía, la fuerza pura y sola"11, mientras la copa ha sido usualmente identificada con el corazón ${ }^{12}$, en tanto que continente de fluidos esenciales para la vida. De tal modo, la copa de Higea fue adoptada como símbolo de la profesión

8 TRENAS, Julio: "Conversación con el escultor Juan de Ávalos", en Juan de Ávalos. Valencia, 1978, s. p.

9 BAZÁN DE HUERTA, Moisés: "Juan de Ávalos: una vida para la escultura”, Ars et Sapientia: Revista de la Asociación de Amigos de la Real Academia de Extremadura de las letras y las artes, 21, 2006, p. 22.

${ }^{10}$ RICHEPIN, M. Juan: Nueva Mitología Griega y Romana (1920). T. II. Barcelona, 1990, p. 208.

${ }^{11}$ CIRLOT, Juan Eduardo: Diccionario de símbolos. Barcelona, 1998, p. 405.

12 Ibidem, p. 149. 
farmacéutica ${ }^{13}$. La lectura iconográfica debe extenderse al árbol situado tras la figura, una pinácea, especie considerada desde la antigüedad como signo de inmortalidad y de fuerza vital, árbol favorito de Démeter o Cibeles, e incluso del propio Asclepio, con frecuentes usos en la farmacopea tradicional.

El realismo idealizado, sereno y trascendente, así como el canon estilizado y la estética clasicista reflejan a la perfección el estilo de Juan de Ávalos. Formalmente, la disposición postural de la figura aparece, de forma más o menos similar, en las primeras versiones de la Prudencia y, sobre todo, de la Justicia para la Cruz del Valle de los Caídos, en el ángel del desaparecido monumento Ángel de la Paz de Valdepeñas (1964), arruinado en 1976 a causa de un atentado reivindicado por el grupo terrorista GRAPO, aunque en éste las piernas no estuvieran paralelas, y, aplicado a un canon femenino, en el Monumento a los arqueólogos Ramón Mélida y Maximiliano Macías (1975), realizado con motivo de la celebración del bimilenario de la ciudad de Mérida. En cuanto a las calidades del tratamiento material, destaca la obtención de unos pretendidos resultados abocetados, cuyo efecto es una "superficie palpitante"14, característica de su etapa de madurez.

En sus rasgos fisionómicos y su desarrollo anatómico, el Trofeo Larma recuerda a figuras de similar formato, tales como el Hombre encadenado, realizado en bronce y expuesto en la sala El Brocense ${ }^{15}$, que tiene su continuación formal en la figura masculina de Encadenados, grupo escultórico presentado en la exposición "Pintores y Escultores españoles por los Derechos Humanos", auspiciada por Cruz Roja Española que se desarrolló entre el 15 y el 30 de noviembre de 1980 en la sala Tiépolo de Madrid, y que podría darnos una imagen final parecida al modo en el que hubiera podido haberse resuelto la pieza de la colección Marroco de haberse llegado a fundir. Existen fuertes concomitancias, de igual modo, con la figura masculina del conjunto Adán y Eva, obra en mármol, y al Hombre de la Montaña, en bronce, ambas exhibidas en la muestra individual de la galería Ribe$\mathrm{ra}^{16}$ en 1977. Esta última obra, junto con el Hombre del Mar, se creó inicialmente para acompañar a la imagen de $\mathrm{La} P a z$, en sendos monumentos de Oviedo y de Benidorm, de 1975. Ambos son buenos ejemplos -aplicable de igual modo a la figura del Trofeo Larma- del canon masculino fomentado por el artista: "musculoso pero al tiempo esbelto y elegante" 17 (Figura 4).

Tanto por la citada inscripción en la base de la escultura, cuanto por las referencias emblemático-simbólicas que han sido analizadas y por el formato y cualidades del material estudiados, sería plausible pensar en la pieza como un modelo

${ }^{13}$ CARMONA CORNET, Anna M. a: "Estudio iconográfico del emblema farmacéutico", El Farmacéutico, 251, 2000, pp. 84-90.

${ }^{14}$ BAZÁN DE HUERTA, M.: Juan de Ávalos: su verdad..., op. cit., p. 51.

15 Juan de Ávalos. [Exposición]. Cáceres, 1976, s. p.

16 Juan de Ávalos. [Exposición]. Valencia, 1977, s. p.

17 BAZÁN DE HUERTA, M.: Juan de Ávalos: su verdad..., op. cit., p. 262. 
para un galardón de la empresa farmacéutica madrileña LARMA (Laboratorios R. Malo de Molina), que por circunstancias desconocidas nunca llegó a materializarse, dada la inexistencia de evidencias de que un trofeo de tal nombre llegase a otorgarse. La citada empresa, LARMA, desarrolló su actividad al menos desde los años cincuenta hasta 2008, año en que cesó su actividad mercantil ${ }^{18}$. Debió ser una empresa pujante gracias a uno de sus productos farmacéuticos más conocidos, el "Peninovel" (Penicilina G), y muy activa en el patrocinio de variadas actividades en distintos ámbitos, desde el auxilio social y la docencia hasta la cultura o el deporte ${ }^{19}$, y que incluso contó con una publicación propia tipo magazine, quincenal, publicada por el Departamento de Publicaciones Científicas de los Laboratorios R. Malo de Molina, que combinaba noticias médicas con reportajes de corte social y cultural, cuyo primer número se publicó el 7 de abril de $1958^{20}$.

Conocemos que, en alguna ocasión, el escultor emeritense aceptó la ejecución de galardones escultóricos institucionales, como el Trofeo homenaje Augusta Emérita (1976), por encargo del Centro de Iniciativas Culturales de Mérida, fechas que concordarían con el desarrollo estilístico y formal a partir de la cual podría datarse el Trofeo Larma, ya que resulta característica a partir de la década de los setenta del pasado siglo "una progresiva orientación hacia la escultura de pequeño formato, campo que le permite trabajar (...) con un aliento delicado e intimista" ${ }^{21}$.

El Trofeo Larma, obra inédita hasta el momento, ayuda a conocer la producción menos conocida de Juan de Ávalos, las realizaciones de pequeño formato y los bocetos en bronce, mármol, piedra, madera, barro o poliéster -material en el que fue pionero en España al usarlo como herramental auxiliar en la obtención positivos escultóricos ${ }^{22}$ - que el mismo denomina "mimos" 23 , algunos de los cuales resultaron modelos para obras de encargo y de los que se conservan muy pocos ejemplos.

Fecha de recepción: 21 de septiembre de 2016

Fecha de aceptación: 4 de enero de 2017

${ }^{18}$ Laboratorios Larma, s.l. aparece en el Registro Mercantil de Madrid como declarada insolvente en 2008 (R.M.M., Referencia 23080, Boletín nº 23, 2008).

19 PÉREZ PEÑA, Fernando: Memoria histórica del Hospital Clínico de San Carlos. T. I. (Estampas y vivencias de la Facultad de Medicina (UCM). Segunda parte, 1965-1984). Madrid, 2014, p. 443.

${ }^{20}$ Col·lecció de Premsa Agustí Pedro Pons (Biblioteca de Catalunya).

${ }^{21}$ BAZÁN DE HUERTA, Moisés: "Juan de Ávalos. Vivir la escultura”, en Juan de Ávalos. Mérida, 2012, p. 28.

${ }^{22}$ BAZÁN DE HUERTA, M.: Juan de Ávalos: su verdad..., op. cit., p. 51.

${ }^{23}$ DE ÁVALOS, Juan: "Debo decir...", en Juan de Ávalos. Valencia, 1977, s. p. 


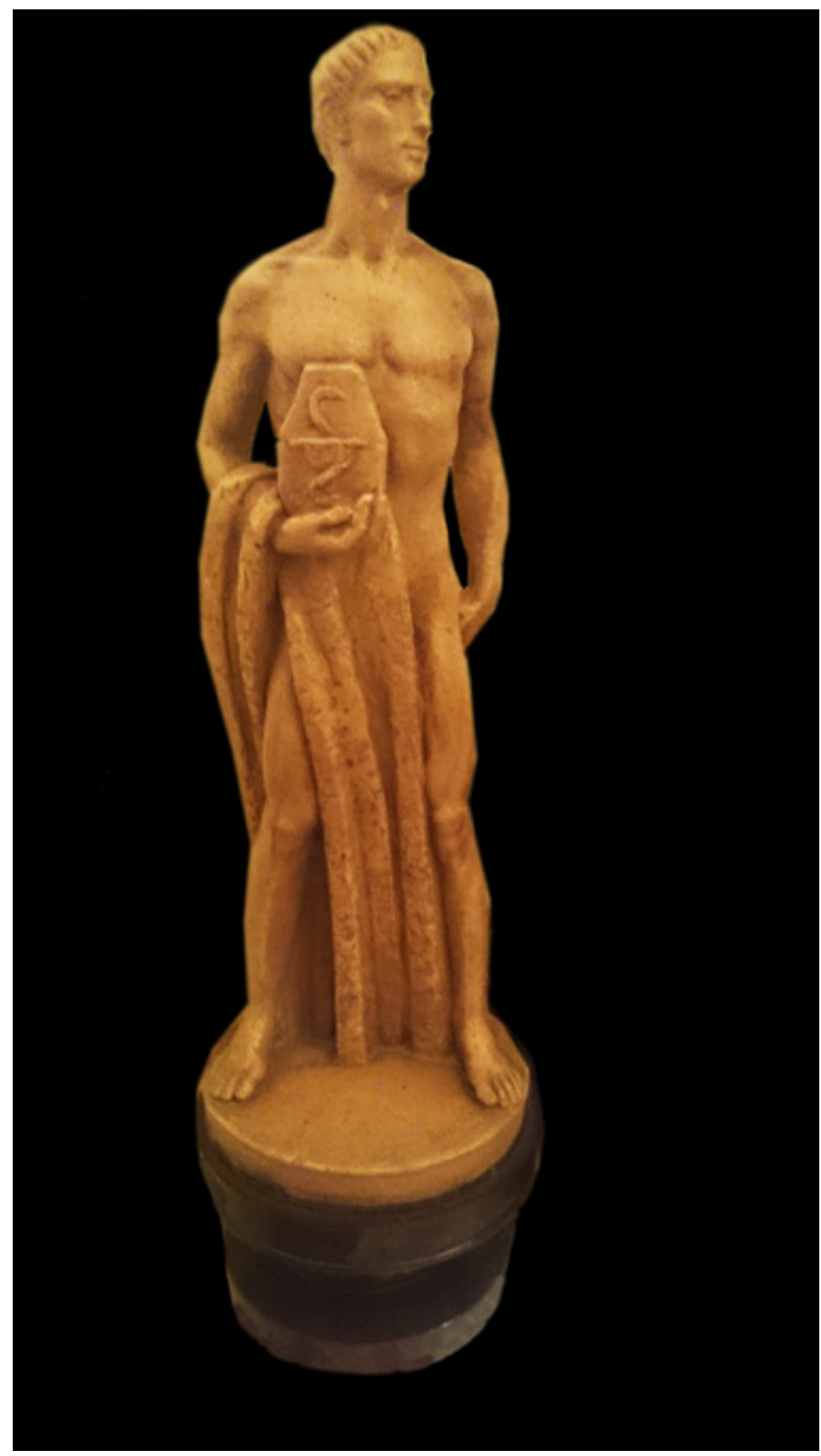

Figura 1. Juan de Ávalos, Trofeo Larma, colección Marroco, Sevilla.

LABORATORIO DE ARTE 29 (2017), pp. 853-860, ISSN 1130-5762 e-ISSN 2253-8305 - DOI http://dx.doi.org/10.12795/LA.2017.i29.50 


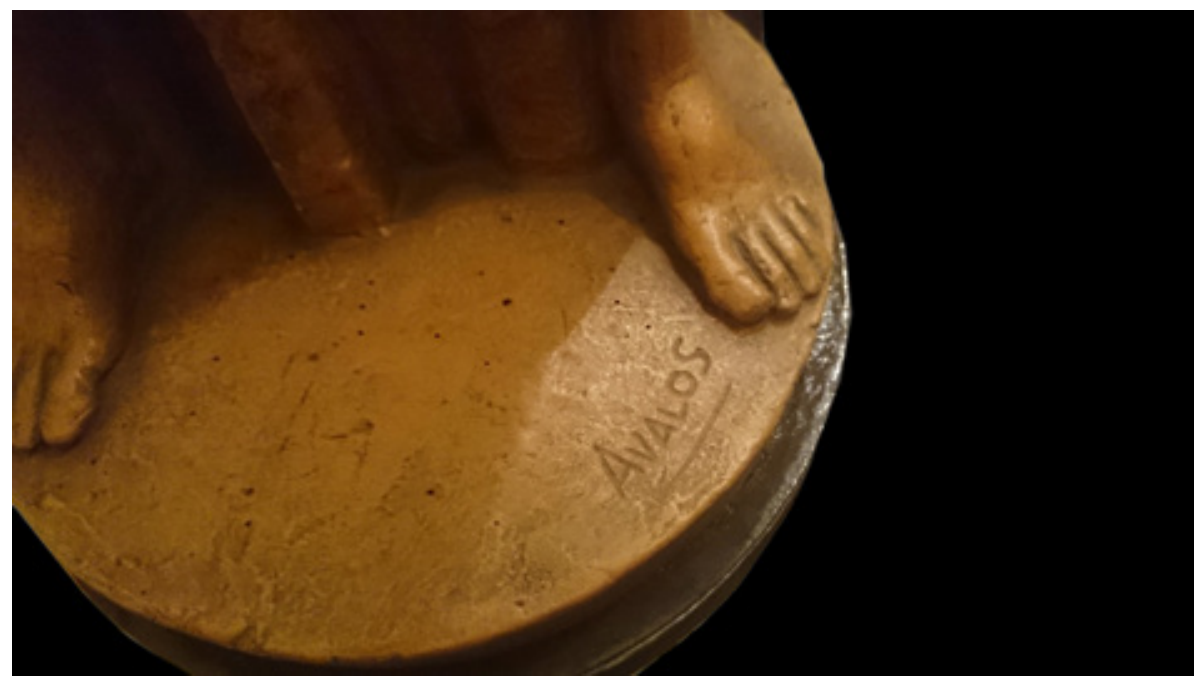

Figura 2. Juan de Ávalos, Trofeo Larma (firma), colección Marroco, Sevilla.

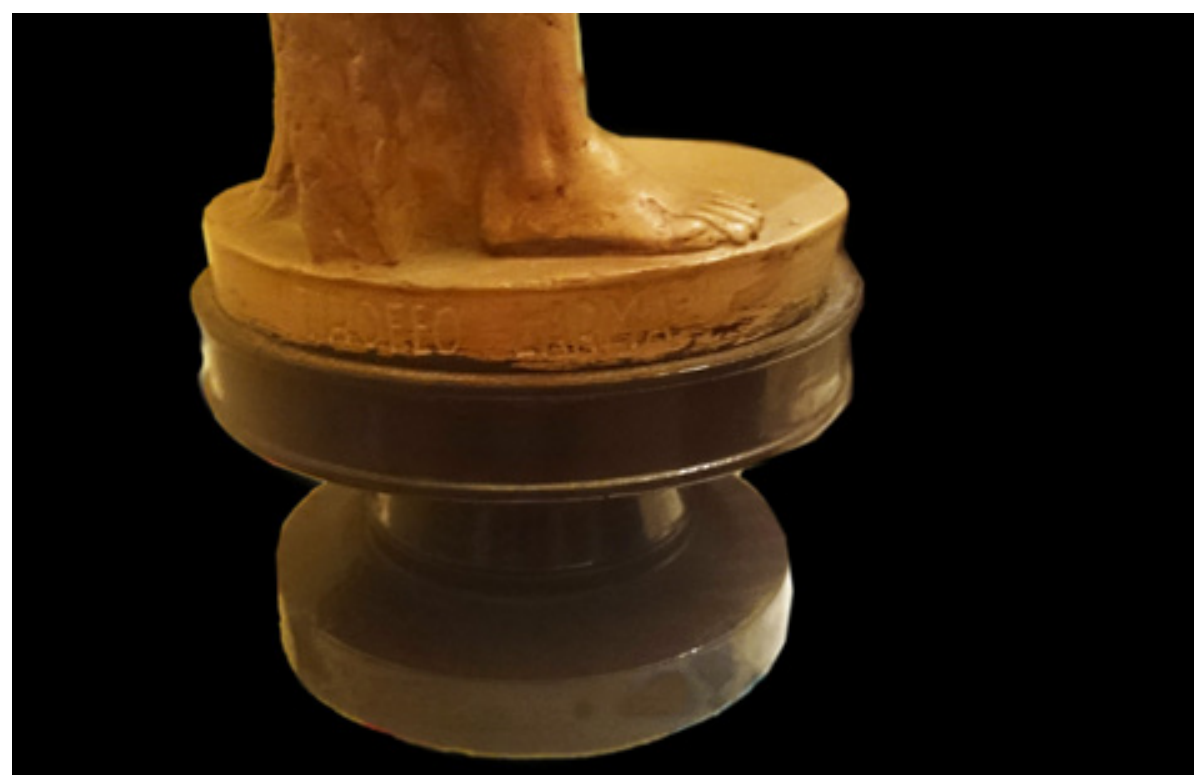

Figura 3. Juan de Ávalos, Trofeo Larma (título), colección Marroco, Sevilla. 


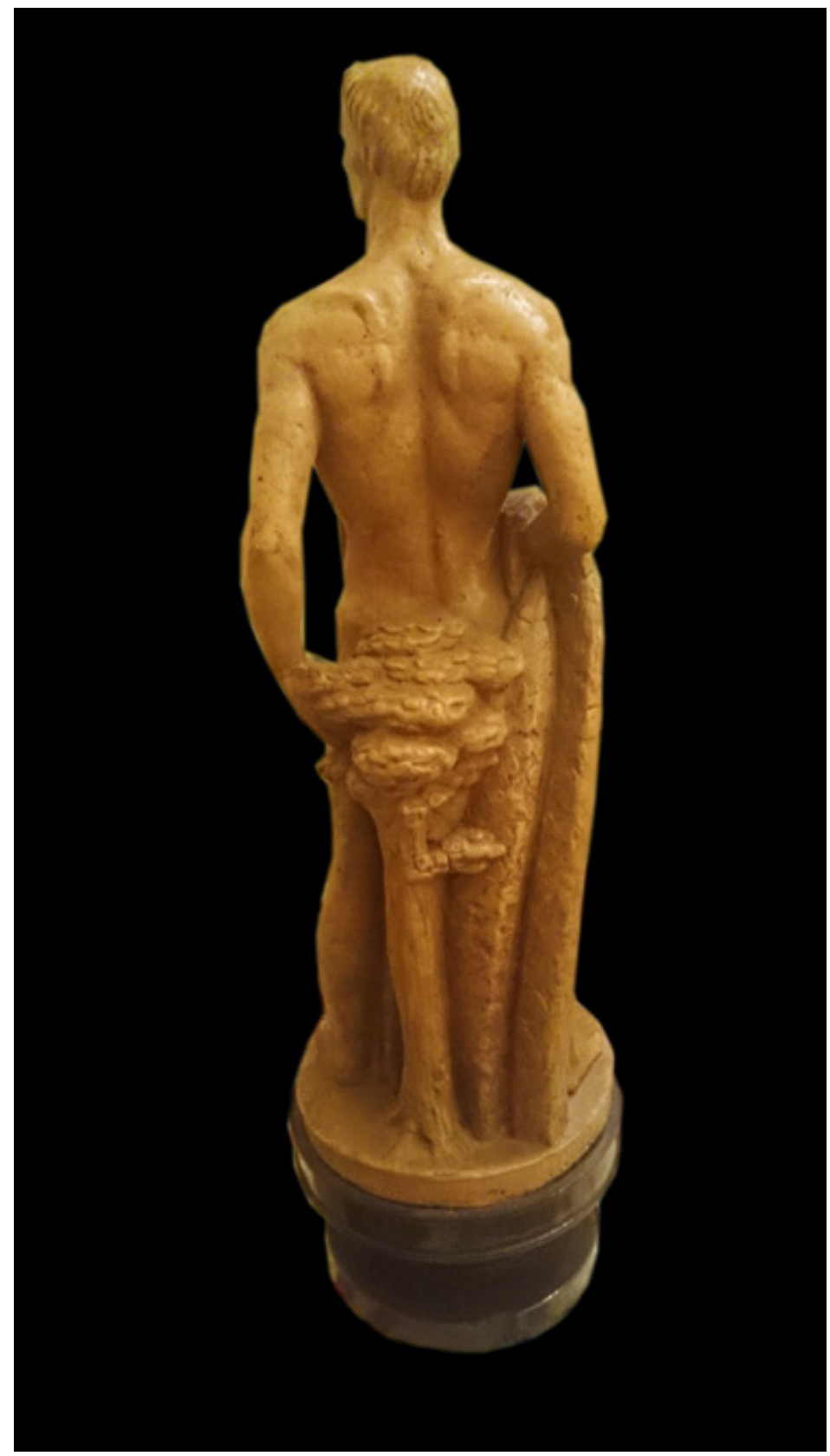

Figura 4. Juan de Ávalos, Trofeo Larma (vista posterior), colección Marroco, Sevilla. 